\title{
OPEN SOURCE APPROACHES TO EDUCTIONAL TECHNOLOGY INNOVATION
}

\author{
An MIT Perspective
}

\author{
Alfred Essa \\ Sloan School, Massachusetts Institute of Technology
}

\begin{abstract}
Universities have a mission to create, preserve, and disseminate knowledge. In realizing that mission, we face significant cultural, legal, economic, and technical pressures. The intellectual commons can be defined as "that shared wellspring of ideas and innovation from which all may freely draw" and its intent is to counteract regimes of control and replace them with regimes of opportunity. The approach to educational technology innovation at MIT seeks to advance the intellectual commons by developing and freely sharing "open content" and "open code". This talk describes MIT's approach to educational technology innovation by examining underlying principles, specifying technical architecture, and demonstrating specific projects. We focus in particular on .LRN, an open source project and platform for supporting innovation in collaborative education and learning and research communities. Originally developed at MIT as part of the intellectual commons, .LRN is now backed by a worldwide consortium of educational institutions, non-profit organizations, industry partners and open source developers.
\end{abstract}

Key words: open source, intellectual commons, .LRN

\section{OPEN SOURCE}

The original design for the Internet was both a technical architecture and a value. Known as the end-to-end principle, it specified that network designers should place intelligence at the ends, keep the network stupid, and allow for smart applications. The end-to-end principle along with open software was the original intellectual commons that created the Internet. The new intellectual commons seeks both to preserve the original vision against 
encroachments and to extend the public domain in ways that promote knowledge and freedom.

\section{2. .LRN}

.LRN is an open source platform for e-learning, providing support for course management, online communities, learning management, and content management applications. In addition, .LRN is a powerful framework and tools for quickly innovating on these applications and building customized solutions. Together these capabilities support the complete "online learning" environment for learning communities and communities of practice in higher education, K-12, government, and non-profit organizations.

The .LRN technology originated at MIT and is rapidly evolving from the collective experience and rigor of hundreds of talented software developers worldwide. The underlying kernel has been in production use for nearly a decade in hundreds of web sites worldwide. Elements of the underlying software infrastructure are at the backbone of the largest and most demanding production environments in the world, including aol.com, mapquest.com, and netscape.com.

.LRN is only one among several initiatives emerging out of MIT as part of the intellectual commons. MIT Open Courseware (OCW) is another educational initiative which makes core teaching materials for all MIT graduate and undergraduate classes available at no cost to Internet users around the world. Currently, course materials from 700 courses are available on the MIT web site. DSpace is another groundbreaking digital library system to capture, store, index, preserve, and redistribute the intellectual output of a university's research faculty in digital format. The base platform is being extended so that it can serve also as a transactional repository for learning objects.

.LRN development is moving simultaneously along four dimensions. First, the base platform is being scaled so that it can be easily deployed and used by organizations small and large. Second, the .LRN technical infrastructure is being extended to allow exchange of learning and research content through intermediate digital repositories such as DSpace. Third, .LRN-based applications are being developed that illustrate the power of shared interactive learning and online communities. Finally, .LRN is being coupled with content initiatives such as MIT Open Course Ware so that organizations can quickly and easily draw on the wealth of free course and research content being developed worldwide. 


\section{CONCLUSION}

The open source movement is moving to a new and exciting phase where end users will now begin to benefit from applications that go beyond the infrastructure examples we are all familiar with, such as Linux and Apache. As Aristotle recognized, knowledge is the central activity of man. It is an end in itself but also a requisite for liberty. MIT's intellectual commons initiatives are intended to promote knowledge by freely sharing content and tools which in turn can be extended by others, thereby becoming a wellspring of continuing innovation. 